\title{
OBTENÇÃO E CARACTERIZAÇÃO DE MEMBRANAS MICROESTRUTURADAS DE QUITOSANA E GLOCOMANANA PARA PRODUÇÃO DE CURATIVOS
}

\author{
R. J. GOMES NETO ${ }^{1}$, G. M. GENEVRO 1 , M. A. de MORAES $^{2}$, M. M. BEPPU 1 \\ ${ }^{1}$ Universidade Estadual de Campinas, Faculdade de Engenharia Química \\ ${ }^{2}$ Universidade Federal de São Paulo, Departamento de Ciências Exatas e da Terra \\ E-mail para contato: r137433@dac.unicamp.br
}

\begin{abstract}
RESUMO - Muitas das lesões causadas à pele são tratadas por curativos. Na fronteira do desenvolvimento desses curativos se encontra o emprego de biopolímeros biodegradáveis, dentre os quais se destacam a quitosana e a glucomanana. A quitosana é um polissacarídeo derivado da quitina que apresenta propriedades cicatrizantes, ação hemostática e atividade antimicrobiana. Já a glucomanana é um polissacarídeo neutro, isolado a partir de tubérculos da Amorphophallus konjac, cujos filmes apresentam alta elasticidade e capacidade de absorção de água. Dessa forma, o presente trabalho tem por objetivo a produção de membranas microestrutradas de quitosana e glucomanana visando a sua aplicação como curativos. As membranas microestruturadas foram produzidas pela adaptação do método de deposição em camada (layer-by-layer) seguida da evaporação de solvente (casting). Blendas foram produzidas visando investigar a compatibilidade entre ambos os polímeros. Os ensaios de caracterização indicaram uma boa compatibilidade entre quitosana e glucomanana e testes mecânicos, de intumescimento e de permeabilidade ao vapor apontaram uma combinação entre propriedades de ambos os polímeros na microestrutura. As propriedades morfológicas, térmicas e químicas de cada polímero foram preservadas na microestrutura, o que pode ser um bom indicativo de que as propriedades cicatrizantes, hemostáticas e de barreira de cada um também puderam ser mantidas, resultando em um novo curativo alto desempenho.
\end{abstract}

\section{INTRODUÇÃO}

A pele, órgão de revestimento externo do corpo, tem como funções a proteção, regulação térmica e sensorial do organismo. Muitas das lesões à pele são comumente tratadas por curativos, os quais variam em forma, material e estrutura conforme a aplicação desejada. Um tipo especial de curativo são os biodegradáveis de ação temporária, os quais são degradados e absorvidos pelo organismo ao longo do processo de cicatrização, não sendo necessária a sua retirada (Sheridan e Tompkins, 1999).

Dentre os materiais que poderiam ser empregados como curativos se encontram os biopolímeros biodegradáveis. Um biopolímero que já vem sendo empregado na construção de curativos de alta performance é a quitosana. A quitosana é um polissacarídeo derivado da quitina, presente na carapaça de alguns artrópodes e de fungos e que apresenta uma serie de propriedades biológicas tais como: ação hemostática, ausência de citotoxicidade, atividade antimicrobiana, biocompatibilidade e cuja clivagem enzimática resulta na formação de compostos cicatrizantes (Mikhailov e Lebedeva., 2007). Outro biopolímero de elevado 
potencial para aplicações regenerativas, porem ainda pouco estudado, é a glucomanana: um polissacarídeo neutro, isolado a partir de tubérculos de Amorphophallus konjac C. Koch, planta típica do sudeste asiático (Gao e Nishinari, 2004). Filmes feitos a partir da glucomanana vêm apresentando excelentes resultados para aplicações como membranas, filmes de revestimento, embalagens e também como matriz de comprimidos e hidrogéis na indústria farmacêutica, além da vasta aplicabilidade no ramo de alimentos (Zhang et al., 2005), sendo que uma característica marcante desses filmes é uma elevada elasticidade. As estruturas moleculares da quitosana e glucomanana estão respresentadas na Figura 1 logo abaixo.

Figura 1 - Estrutura molecular da Quitosana (a) e da Glucomanana (b)

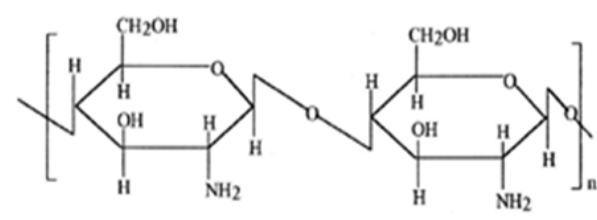

(a)

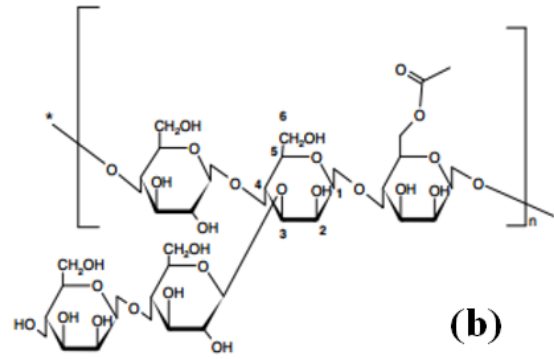

(b)

Membranas microestruturas de biopolímeros podem ser construídas a partir de uma adaptação do método de deposição de camadas layer-by-layer, comumente empregado na produção de nanofilmes. O processo básico do método layer-by-layer envolve a imersão de um substrato, preferencialmente carregado eletricamente, em uma solução diluída de um polieletrólito de carga oposta. Esse mesmo substrato pode ser submetido a uma etapa de lavagem e uma nova imersão numa solução de polieletrólito de carga oposta ao do primeiro. A repetição desta sequência de processos de adsorção de polieletrólitos leva à formação de uma membrana multicamada (Decher et al., 2002).

Para a produção de membranas em escala micrométrica, pode-se utilizar o processo de evaporação de solvente ou casting, ao invés do processo de imersão em soluções de polieletrólitos carregados (Paiva, 2009). Nesse novo processo, uma solução do polímero é posta sobre uma superfície de vidro ou poliestireno e o solvente evaporado até um valor desejado. Em seguida, uma solução de um segundo polímero é posta sobre a superfície do primeiro e o solvente novamente evaporado. Esse ciclo pode ser repetido varias vezes resultando na formação de membranas densas e microestruturadas, com a vantagem de poder ser empregado mesmo para polímeros não carregados.

\section{OBJETIVO}

O presente trabalho tem o objetivo principal a produção de membranas microestruturadas de quitosana e glucomanana pelo método layer-by-layer visando a sua aplicação como curativos de alta performance.

Em adição, blendas em diferentes proporções de quitosana e glucomanana foram produzidas visando analisar a compatibilidade entre ambos os polímeros.

\section{MATERIAIS E MÉTODOS}




\subsection{Preparo das soluções de Quitosana e Glucomanana}

Uma solução de quitosana foi preparada na concentração de $1,0 \%(\mathrm{~m} / \mathrm{m})$ dissolvendo-se a quitosana extraída da carapaça de caranguejo em uma solução de ácido acético 3\% (v/v) e mantendo o sistema sob constante agitação por cerca de $12 \mathrm{~h}$, seguida de uma filtração a vácuo. Essa foi neutralizada com um solução de hidróxido de sódio $1 \mathrm{~mol} . \mathrm{L}^{-1}$ até $\mathrm{pH} 5,5$, Uma solução de glucomanana foi preparada na concentração de $0,8 \%(\mathrm{~m} / \mathrm{m})$ pela dissolução da farinha de Konjac em água, sob uma agitação do tipo shaker por $8 \mathrm{~h}$.

\subsection{Preparo das Blendas de Quitosana e Glucomanana}

As soluções de quitosana e glucomanana $1 \%(\mathrm{~m} / \mathrm{m})$ foram misturadas em diferentes frações de quitosana/glucomanana: CHI - 100/0, CK1 - 75/25, CK2 - 50/50, CK3 - 25/75 e KGM- 0/100, de forma que a massa seca da mistura fosse de $2 \mathrm{~g}$. Em seguida, essas soluções foram espalhadas sobre placas petri de policarbonato e colocadas em estufa a $50 \pm 3^{\circ} \mathrm{C}$ para evaporação do solvente até que não mais se observasse alteração da massa. As membranas assim obtidas foram imersas em uma solução aquosa de hidróxido de sódio $(\mathrm{NaOH} 1 \mathrm{~mol} / \mathrm{L})$ por $24 \mathrm{~h}$ a $25^{\circ} \mathrm{C}$, visando a sua estabilização, e depois lavadas com água destilada até que o $\mathrm{pH}$ da água de lavagem ficasse entre 6 e 8. Depois de secas, as membranas foram armazenadas num dessecador com sílica.

\subsection{Preparo das Membranas Microestruturadas de Quitosana e Glucomanana}

Primeiramente, espalhou-se da solução de quitosana sobre uma a placa de Petri de forma que a massa seca fosse de $1 \mathrm{~g}$. As placas foram então colocadas em uma estufa a $50{ }^{\circ} \mathrm{C}$ para evaporação do solvente. A solução de glucomanana foi adicionada à placa quando $70 \%$ da massa do solvente tivessem evaporado, criando assim uma interface aquosa para interação entre as duas soluções poliméricas. Em seguida, evaporou-se até massa constante toda a solução presente na placa. A membrana microestruturada assim obtida foi estabilizada com $\mathrm{NaOH} 1 \mathrm{~mol} / \mathrm{L}$ e neutralizada conforme procedimento indicado anteriormente para as demais membranas.

\subsection{Caracterização das Membranas}

Foram realizadas análises químicas, térmicas, morfológicas e cristalográficas das blendas e microestruturas empregando-se respectivamente: Espectrometria no Infravermelho com Transformada de Fourier (FT-IR), Calorimetria Exploratória Diferencial (DSC), Microscopia Eletrônica de Varredura (MEV) e Difração de Raios-X (DRX).

Para avaliar os potencias das membranas microestruturadas com curativos foram realizados testes mecânicos de Resistência à Tração e Percentual de alongamento de acordo com a norma ASTM D882-95a, bem como testes de Permeação ao Vapor da Água e Grau de Intumescimento pela norma ASTM E 96/E 96M (2005).

\section{RESULTADOS}



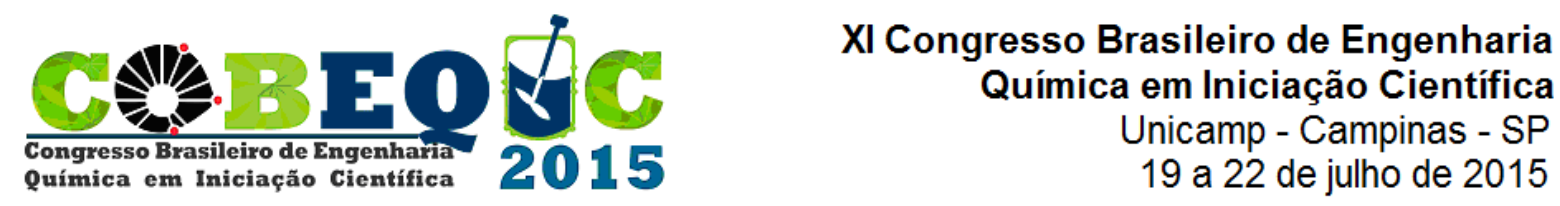

As membranas microestruturadas foram caracterizadas morfologicamente empregando a Microscopia Eletrônica de Varredura, sendo que análises de fratura foram realizadas com o objetivo de analisar a interface entre a membrana de quitosana e a de glucomanana.

Figura 2 - Micrografias da fratura (a); da superfície inferior (b) e superior (c) da bicamada de quitosana e glucomanana obtida por casting.
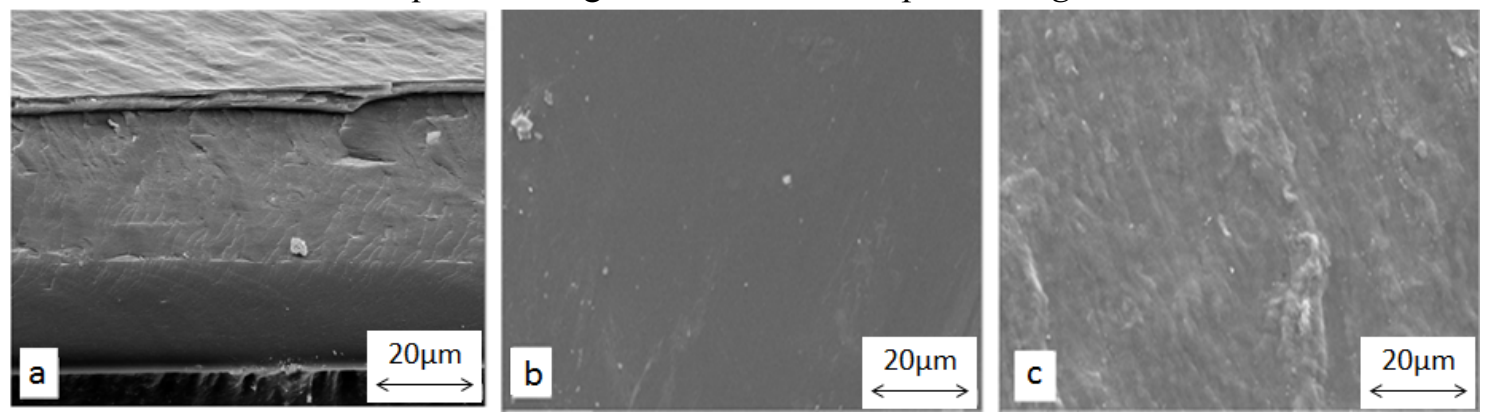

Observando as micrografias da Figura 2, observa-se que o processo de layer-by-layer empregando o casting deu origem a uma membrana de quitosana/glucomanana com uma interface bem definida (a). Em adição, cada superfície manteve a morfologia similar ao correspondente polímero puro: quitosana na parte inferior (b) e glucomanana na parte superior (c). Esse pode ser um bom indicativo que as propriedades morfológicas e superficiais de cada polímero puderam ser preservadas.

Com o objetivo de analisar as interações entre quitosana e a glucomanana, foram realizadas análises de Espectrometria no Infravermelho por Transformada de Fourier e Calorimetria Exploratória Diferencial de todas as membranas. A cristalinidade dessas membranas também foi investigada empregando a Difração de Raios-X.

Figura 3 - Espectros de Infravermelho (a), Curvas de DSC (b) e Alos de Difração de Raios-X (c) das blendas e Microestruturas.

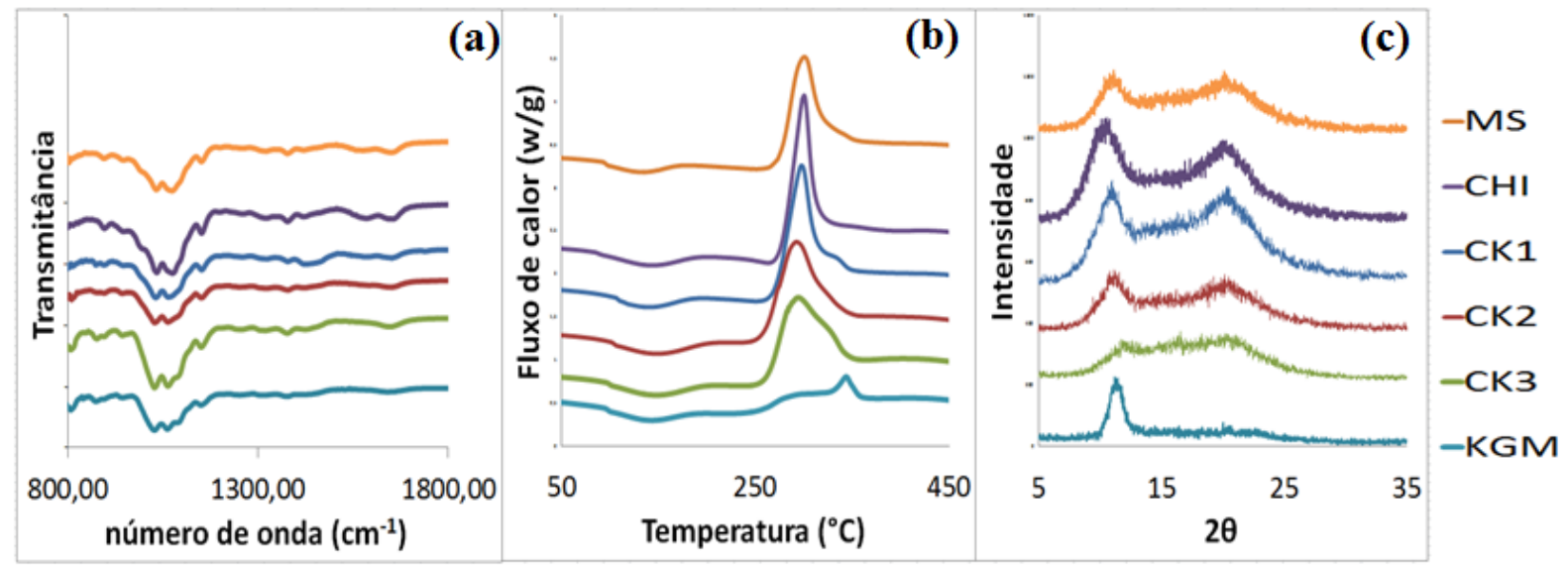

Para as blendas (CK1, CK2 e CK3) verifica-se que conforme aumentamos a proporção de glucomanana, há desaparecimento gradativo da banda intensa em $1082 \mathrm{~cm}^{-1}$ presente no filme de quitosana puro, o que pode indicar a ocorrência de uma interação entre a glucomanana e a quitosana. Em adição, o pico $1638 \mathrm{~cm}^{-1}$ característico do alongamento das ligações de hidrogênio intramolecular são ligeiramente descolados para um numero maior 
conforme aumentamos a concentração de glucomanana, indicando que novas interações de hidrogênio ocorreram entre a quitosana e a glucomanana (Ye et al., 2005). Para a membrana microestrutura (MS), não foi verificada alterações nos espectros característicos da quitosana e da glucomanana o que pode ser um bom indicativo de que as propriedades químicas de cada biopolímero puderam ser preservadas.

As curvas de DSC foram usadas para determinar a compatibilidade entre a quitosana e a glucomanana por meio dos picos endotérmicos das blendas e das microestruturas. As curvas de DSC das blendas exibiram propriedades térmicas intermediárias entre os dois polímeros, com as temperaturas de decomposição ligeiramente afastadas das dos polímeros puros. Esse desvio das temperaturas de decomposição indica que a quitosana e a glucomanana formam ligações de hidrogênio entre si (Ye et al., 2005). Já a microestrutura densa apresentou os dois picos endotérmicos nas mesmas temperaturas que as dos polímeros puros, indicando a manutenção das propriedades térmicas de cada um.

Analisando os difratogramas de raios $\mathrm{X}$, verifica-se que todas as membranas apresentaram uma estrutura predominantemente amorfa. Tanto para blendas tanto para as microestruturas, verificou-se uma diminuição da intensidade dos halos de cristalinidade de ambos os polímeros. Isto indica que a formação das estruturas dessas membranas se dá de maneira amorfa, ou seja, as estruturas cristalinas dos dois biopolímeros não interagem uma com a outra e as interações intermoleculares ocorrem somente na região amorfa.

Testes mecânicos de Resistência à Tração e Percentual de Alongamento, bem como testes de Intumescimento, Permeação e Transmissão ao Vapor da Água foram utilizados o potencial uso das microestruturas como curativos.

Tabela 1 - Valores de transmissão (TVA) e permeabilidade ao vapor d'água (PVA), grau de intumescimento e dos testes mecânicos das membranas.

\begin{tabular}{crllrllrlll}
\hline & \multicolumn{3}{c}{ CHI } & \multicolumn{3}{c}{ KGM } & \multicolumn{3}{c}{ MS } \\
\cline { 2 - 10 } TVA (g/m².day) & 254.2 & \pm & 80.5 & 282.6 & \pm & 66.3 & 211.0 & \pm & 28.7 \\
PVA (g.mm/m ${ }^{2}$.day.kPa) & 5.7 & \pm & 0.2 & 5.8 & \pm & 1.2 & 5.6 & \pm & 0.2 \\
Intumescimento (\%) & 181.0 & \pm & 11.7 & 495.7 & \pm & 40.2 & 267.9 & \pm & 29.1 \\
Tensão na ruptura (MPA) & 54.7 & \pm & 12.0 & 25.2 & \pm & 18.7 & 50.8 & \pm & 19.8 \\
Alongamento (\%) & 5.2 & \pm & 2,7 & 3.2 & \pm & 2,0 & 2.9 & \pm & 0,8 \\
\hline
\end{tabular}

Analisando os dados da Tabela 1 verifica-se que as microestruturas apresentaram propriedades intermediárias ou estatisticamente equivalentes $(p>0,05)$ em relação aos polímeros puros, não sendo verificada, portanto, interações negativas entre ambos os polímeros.

Sabendo-se que a pele humana normal apresenta tensão de ruptura que varia de 2,5 a 16 MPa (Silver, 1994) e uma permeabilidade ao vapor d'água de $204 \pm 12 \mathrm{~g} / \mathrm{m}^{2} \mathrm{dia}$, pode-se dizer que membrana microestruturada de quitosana e glucomanana apresenta características adequadas para ser empregada como curativo nos que diz respeito a essas duas propriedades.

\section{Conclusão}


Membranas microestruturas de quitosana e glucomanana puderam ser produzidas pela adaptação do método de deposição em camada layer-by-layer, seguido do processo de casting. Análises de MEV revelaram uma boa compatibilidade entre as camadas das microestruturas, as quais apresentaram interfaces bem definidas e propriedades superficiais características de cada polímero. Os resultados de DSC e FTIR apontaram a existência de interações entre a quitosana e glucomanana, podendo ser identificadas ligações de hidrogênio. Pelas análises de DRX foi possível identificar que essas interações ocorrem nas partes amorfas das cadeias, sendo preservados os principais halos de cristalinidade de cada polímero. Os testes mecânicos, de intumescimento e de permeabilidade ao vapor apontaram uma combinação entre propriedades da quitosana e a glucomanana nas microestruturas. Assim, as membranas microestruturadas de quitosana e glucomanana demonstram um elevado potencial para serem aplicadas como curativos de alto desempenho, sendo a combinação dos processos de layer-by-layer e casting, um importante método para construção e aprimoramento da produção dessas membranas.

\section{BIBLIOGRAFIA}

DECHER, G. S., Schlenoff, J. B. Multilayer Thin Films: Sequential Assembly of Nanocomposite Materials. Weinheim: Wiley-VCH, 2002.

GAO, S. J.; NISHINARI, K. Effect of deacetylation rate on gelation kinetics of konjac glucomannan. Colloids and Surfaces B-Biointerfaces, v. 38, p. 241-249, 2004.

MIKHAILOV, G. M.; LEBEDEVA, M. F. Procedures for preparing chitin-based fibers. Russian Journal of Applied Chemistry, v. 80, n. 5, p. 685-694, 2007.

SHERIDAN, R.L. e TOMPKINS, R.G. Skin substitutes in burns. Burns, v.25, p.97-103, 1999.

SILVER, F.H. Wound dressings and skin replacement. In: Biomaterials, Medical Devices and Tissue Engineering: an Integrated Approach. Chapman \& Hall, London, p.46-91, 1994

XIAO, C; GAO, S; WANG, H; ZHANG, L; Blend Films from Chitosan and Konjac Glucomannan Solutions, Journal of Applied Polymer Science, Vol. 76, p. 509-515, 2000.

YE, X; KENNEDY J.F; LI, B ; XIE, B.J; Condensed state structure and biocompatibility of the konjac glucomannan/chitosan blend films, Carbohydrate Polymers, v. 64, p. 532-538, 2006.

ZHANG, Y.Q; XIEA, B.J; GAN, X; Advance in the applications of konjac glucomannan and its derivatives. Carbohydrate Polymers, v. 60, p. $27-31,2005$.

PAIVA, R. G. ; BEPPU, M. M. Production and characterization of chitosan and alginate multilayer membranes containing copper., 2007 National Meeting, 2007. 